\title{
Recycled Concrete Used in Subbase in Potential Use for Road Base and Cement Bounded Material (CBM)
}

\author{
Hassan Haidar Ahmad \\ hhaidarahmad@gmail.com \\ Al Jaber Hadid Construction, Doha, Qatar
}

\begin{abstract}
Structure life cycle and economic developments in Qatar can lead to reconstruction as well as demolition of structures such as buildings and roads. One of the main wastes from demolition work is concrete and reinforced concrete. Concrete dumped as waste in landfills in Qatar, so this paper will emphasis utilizing the concrete waste through means of recycling and reusing in the road construction market. Qatar's benefit is to decrease pollution, generating economic benefits and become more self-sustainable and save its existing resources. This paper will focus on the fine recycled concrete (FRC) $0-5 \mathrm{~mm}$ as a fine aggregate material in the mix design for constructing the base road layers under the Asphalt layers and how using crushed concrete can increase the quality and change the classification of the base aggregate mixes. After the process of concrete crushing, the crushed material will be produced and used as fine aggregate in a fixed amount of fine crushed concrete which can improve the properties of the mix design for base road construction (aggregate base) produced in different production dates. This can decrease the use and import of sand (dune sand and washed sand) from overseas, in the mix designs for Subbase, Road Base and Cement bounded material (CBM) and increase the quality in Qatar. The paper will verify the use of fine crushed concrete (FRC) in the aggregate mixes to upgrade the quality of the fine aggregate material used in the road construction (Goonan, 1998).
\end{abstract}

Keywords: Recycled concrete; Sub-base; Road base; Cement bounded material

\section{INTRODUCTION}

Finding purposes for waste materials are more popular by reuse and recycle process. This is due to a shortage of aggregate sources, increasing waste cost, and increasing the demand of material, so crushing the aggregates for the construction purposes makes an impact on resource due to demand of material and environmental degradation, in addition, the recycled materials create many economic and environmental benefits. Fine Crushed concrete can be considered as an alternative solution and a useful source of aggregate for the construction industry in Qatar. International research has been revealed that recycled concrete aggregates can be applied complete or incomplete. However, they had proven that the fine portion of Recycled Concrete makes intangible effects on the mix properties of base aggregate material.

Throughout this study, it is evident that using recycled crushed concrete for the fine portion of the base aggregate design mixes which prove ideal for the full mix by improving the mix design quality. As stipulated by QCS 2014 and the range of materials to be used, crushed concrete can be utilized for subbase road base and CBM; for example, 
when using crushed concrete in the $0-5 \mathrm{~mm}$ content of a mix design for subbase, the properties improve the whole design to satisfy the requirements for road base and CBM.

Fine recycled concrete classifications should be taken in consideration for the variability of material consistency, performance, and evaluation for the characteristics of an unbounded and bounded material constructed using the fine recycled concrete and subjected to real traffic loading. This paper presents the results for classification tests of six different mixes samples to analyse the feasibility of using the FRC material in unbounded material (subbase \& Road base) mixes comparing their classification properties with the original unbound aggregate materials used in Qatar.

\section{MATERIAL DESCRIPTION}

In this paper, one available fine recycled concrete product, obtained from a crusher plant in Qatar. Material sources are crushed from the waste of concrete of the building. The collected materials are undergone a normal crushing process to produce fine recycled concrete. Table 1 shows the maximum and the minimum percentages of the coarse and fine aggregate that create subbase and Road base as unbounded material. These three aggregate materials sizes were blended in a fixed combined aggregate percentage by weight of the total mix from different date production to form six samples which represent a combination of fine and coarse aggregates Table 2 shows the combined aggregate percentages, original sample was used for the purpose of comparing the properties of the mixes which prove the consistency for the produced material (Kelly \& Thomas, 1996).

Table 1: Minimum and Maximum Percentage in Mix

Maximum and minimum limits of each Constituent (percentage by mass)

\begin{tabular}{|l|l|l|l|}
\hline & $\begin{array}{l}\text { Coarse } \\
\text { Aggregate }\end{array}$ & $\begin{array}{l}\text { Fine } \\
\text { Aggregate }\end{array}$ & $\begin{array}{l}\text { Fine Recycled } \\
\text { Concrete FRC }\end{array}$ \\
\hline $\begin{array}{l}\text { Road base \& } \\
\text { Subbase }\end{array}$ & $70-65$ & $15-14$ & $20-16$ \\
\hline
\end{tabular}

*FRC-Fine Recycled Concrete

Table 2: Combined Blending Percentages

\begin{tabular}{|c|c|c|c|c|c|c|c|}
\hline Size in mm & $\mathbf{5 0 . 0}$ & $\mathbf{3 7 . 5}$ & $\mathbf{1 9 . 0}$ & $\mathbf{9 . 5}$ & $\mathbf{4 . 7 5}$ & $\mathbf{0 . 6 0 0}$ & $\mathbf{0 . 0 7 5}$ \\
\hline $\begin{array}{c}\text { Original } \\
\text { material (no } \\
\text { FRC) }\end{array}$ & 100.0 & 100.0 & 75.2 & 58.7 & 42.9 & 15.8 & 3.5 \\
\hline Mix 1 & 100.0 & 100.0 & 85.9 & 68.0 & 44.5 & 18.1 & 3.7 \\
\hline Mix 2 & 100.0 & 100.0 & 77.5 & 59.2 & 39.5 & 14.2 & 3.1 \\
\hline Mix 3 & 100.0 & 98.7 & 76.6 & 63.4 & 43.5 & 20.5 & 8.9 \\
\hline Mix 4 & 100.0 & 98.9 & 73.7 & 55.3 & 41.4 & 16.8 & 5.0 \\
\hline Mix 5 & 100.0 & 100.0 & 72.6 & 60.0 & 48.7 & 17.5 & 2.8 \\
\hline Mix 6 & 100.0 & 100.0 & 84.4 & 63.6 & 41.5 & 18.3 & 4.6 \\
\hline $\begin{array}{c}\text { Average of } \\
\text { results }\end{array}$ & 100.0 & 99.6 & 78.5 & 61.6 & 43.2 & 17.6 & 4.7 \\
\hline $\begin{array}{c}\text { Minimum as per } \\
\text { QCS 2014 S6 p4 }\end{array}$ & 100 & 95 & 70 & 50 & 35 & 12 & 0 \\
\hline $\begin{array}{c}\text { Maximum as } \\
\text { per QCS 2014 } \\
\text { S6 P4 }\end{array}$ & 100 & 100 & 92 & 70 & 55 & 25 & 8 \\
\hline
\end{tabular}




\section{LABORATORY TESTING AND RESULTS ANALYSIS}

Usually fine recycled concrete (FRC) materials are highly inconsistent and include different amounts of impurities and their quantities are not cumulative. This makes FRCs have a specific classification property, so to characterize the properties of FRCs through classification tests such as sieve analysis test, Atterberg limits test, Sand equivalent, to investigate the possible range of material properties that lead to pursuing the use specific material in the related mix. The results were compared with the minimum or maximum acceptable requirements for subbase and road base materials as per Qatar Construction Standards (QCS, 2014, section 6 part 4).

\section{MATERIAL SIZE DISTRIBUTION TEST}

Aggregate size distribution of an unbounded material mix type affects its Atterberg limits, Sand equivalent, and maximum dry density (MDD) so the size distribution of soil aggregate is important because the size of the aggregate determine their susceptibly to movement (erosion) so the gradation results of all six mixes obtained from material size distribution analysis are shown in Figure 1.

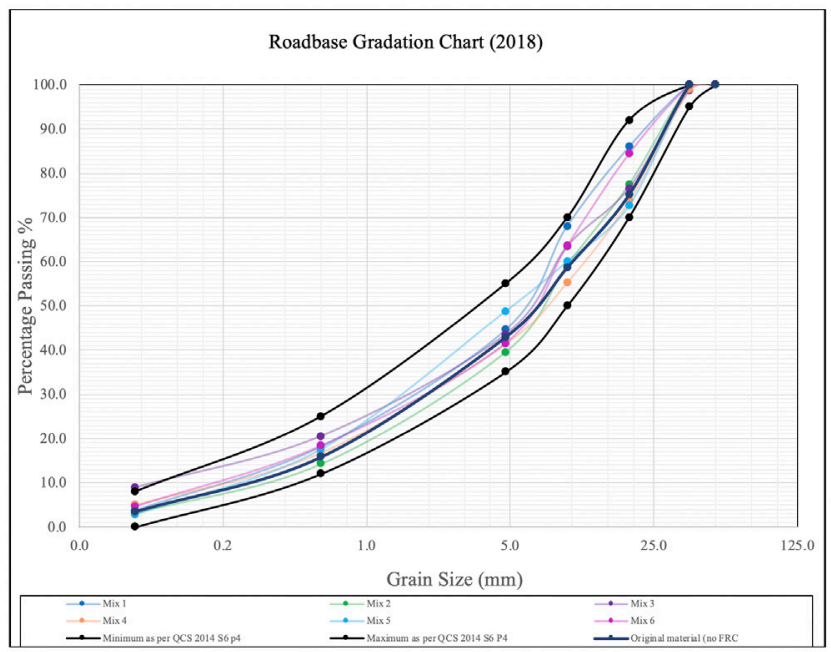

Figure 1: Gradation Curves for The Six Mixes with The Limits Required QCS 2014 S6 P4

As shown from the graph that all samples were equivalent in the size distribution and satisfy the requirements as per QCS 2014 section 6 part 4 (Table 4.4)

\section{ATTERBERG LIMITS TEST}

The Atterberg limits test is a basic test used to find the critical water contents for finegrained soil. Casagrande method as per ASTM D4318 was used to determine the liquid limit test (LL) as well as plastic limit test (PL) for the 6 samples with FRC typical sample used, these results help in proposing the design of the road and to show the behavior of soil material in road construction in another word under the layers of road asphalt.

Liquid Limit is the limiting water content at which reactive soil changes from a liquid to a plastic status and the Plastic Limit is the limiting water content at which reactive soil changes from a plastic to a semisolid state so Plasticity Index (PI). The 
higher PI the higher clay content.

The liquid limit (LL) and the plastic limit (PL) test values were summarized in Figure 2. According to QCS (2014) specifications, the maximum Liquid limit is $25 \%$ \& the plasticity index (PI) is $6 \%$ for Road base and subbase layers and FRCs material show it is Non-plastic.

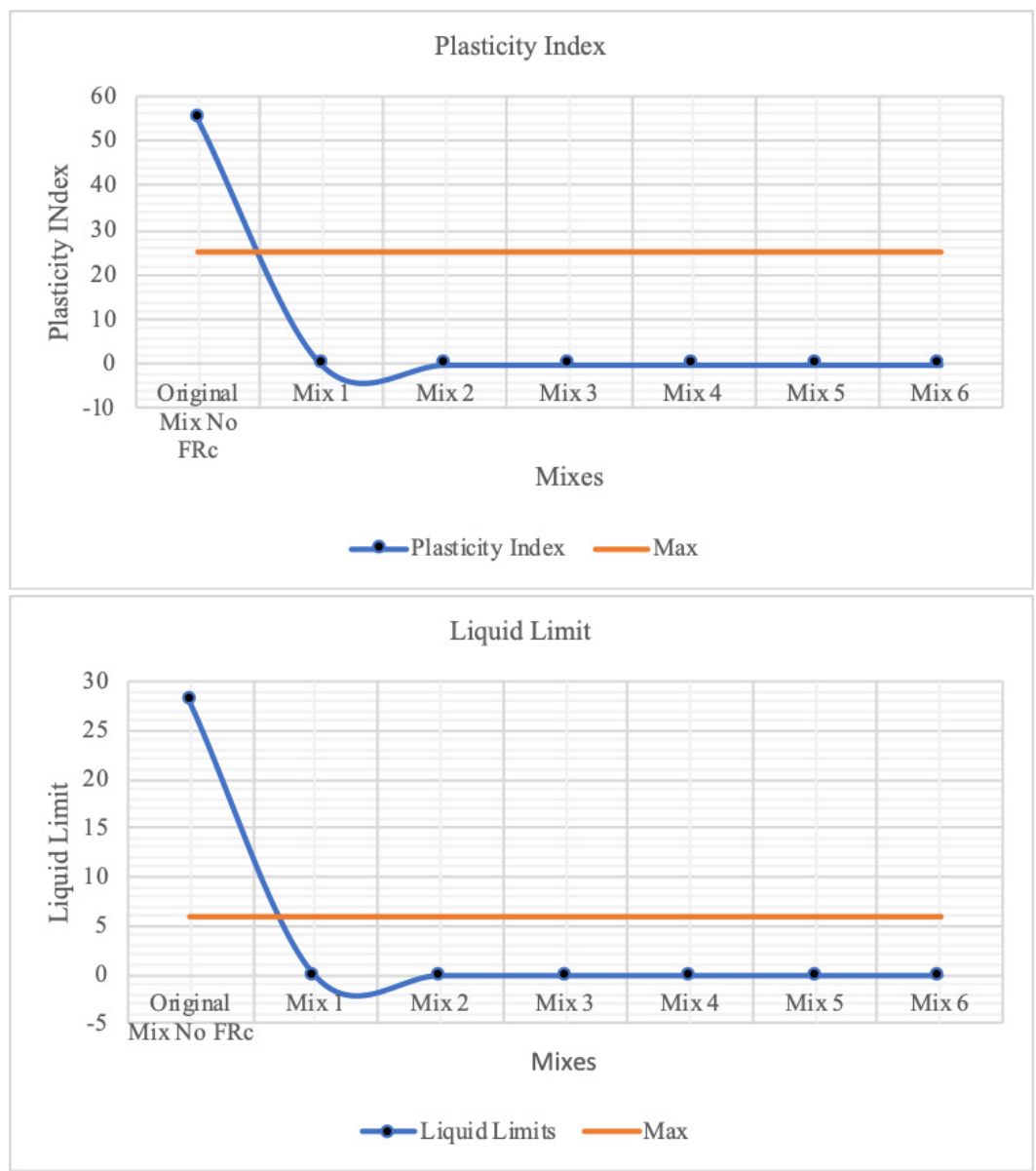

Figure 2: Summary of Plasticity Index and Liquid Limit Tests

As shown from the graph, adding the FRC content substantially improved the samples when compared with the opriginal material where no FRC and all mixes fall below the maximum limit requiored by (QCS, 2014) section 6 part 4 (table 4.1).

\section{SAND EQUIVALENT TEST}

The sand equivalent test is a test that shows the attributes of the fine clay in the fine aggregate. The sand equivalent test delineates that most of the fine aggregates are mixtures from the fine waste of coarse particles and generally reactive clay and the characteristics of clay-like material present. As a specific description the sand equivalent test, a sample of aggregate will be prepared from the fine aggregate and then added to cylinder with a specific solution to separate the fine and the coarse aggregate of the fine aggregate passing the $4.75 \mathrm{~mm}$ then additional separation will be done by adding the 
cylinder to a mechanical shaker which will lead to a total separation of dust from the fine aggregate, so the sand equivalent test dominate on calculating the percentage of sand equivalent from the sand reading over the clay reading, so higher sand equivalent reflect to two parts first that the material contains less amount of dust and second the material contain high sand amount in the fine aggregate but this will not clarify the cleanness of the material because there is high sand equivalent for some materials but the clay content is destructive for the material and the mix.

The Sand equivalent test method is done as per ASTM D2419 and it is used for the original material FRC and the 6 mixes and the values are summarized in Figure 3. According to QCS (2014) specification, the minimum limit for Sand equivalent for subbase is $25 \%$ and for Road base is $35 \%$ but all the mixes were done to satisfy subbase and road base mix without any additional charge on the material cost.

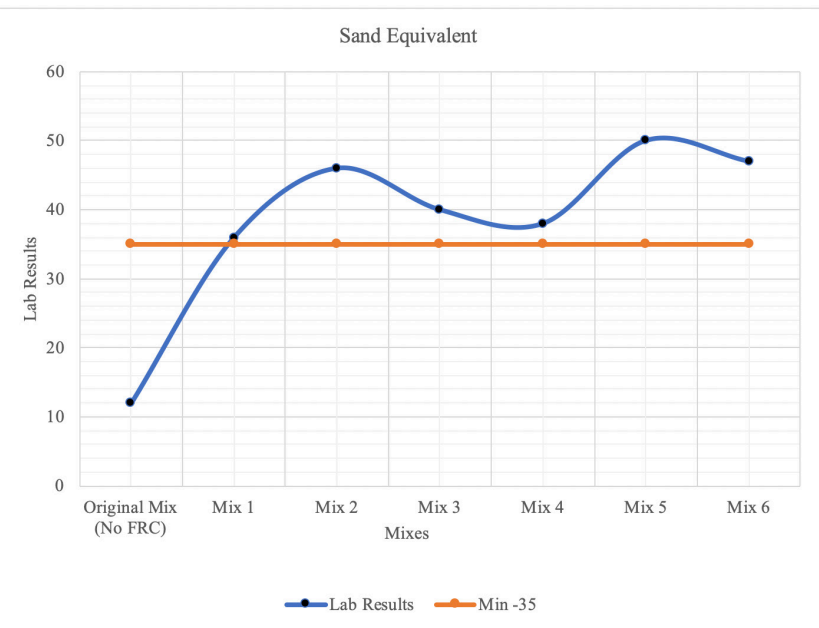

Figure 3: Sand Equivalent Tests Results

\section{MAXIMUM DRY DENSITY (MDD) TEST}

The compacted soil must be stable enough to carry the traffic load without any undesirable settlements or even deformation of the surface for the compacted soil during the laying process and during the construction period. The compacted soil is tested onsite by the nuclear density machine (NDT) and use the maximum dry density with the moisture content. This soil is compacted with reference to the MDD prepared from a sample collected for the construction site, tested and verified by site laboratory. The percentage of compaction required for the soil is $100 \%$ in the constructed area but sometimes the result of the compaction varies from one location to another location in the same site even if the same material and same mix is used. So, the percentage amount $100 \%$ for compaction which is required by (QCS, 2014) S6P4 should be conducted by the MDD tested from the approved lab and verify the $100 \%$ compaction.

The Maximum Dry Density (MDD) for a soil calculated upon the effect of moisture towards the density of the material. Unbounded material is affected by the variations in the moisture content specified if the mix is a coarser or a finer mix. The standard proctor compaction test in accordance ASTM D1557 was performed on each produced sample. 
Optimum Moisture Content (OMC) and Maximum Dry Density (MDD) values for each mix are summarized in Figure 4. The specification of MDD and OMC for Road base and subbase are $2.15 \mathrm{mg} / \mathrm{m} 3$ and $2.05 \mathrm{mg} / \mathrm{m} 3$, respectively. It can be seen that both MDD and $\mathrm{OMC}$ are affected by the mix gradation in case the mix is finer this provide that more fines can absorb more water and can decrease the voids created from the large aggregate sizes, moreover, the fine in the samples are more pointed showing the sensitivity of mixture for water.

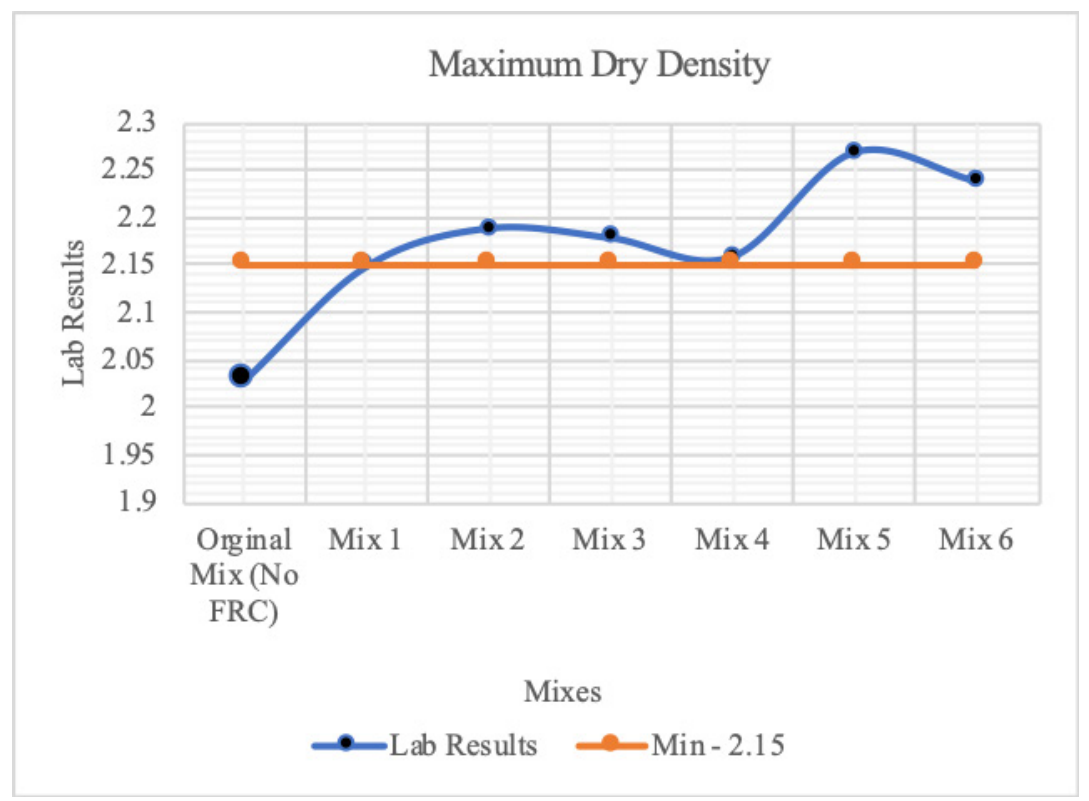

Figure 4: Maximum Dry Density Tests Results

From the graph, adding the FRC to the original material clearly upgraded the MDD from the low unaccepted value as per the minimum limits required in the (QCS,) 2014 section 6 part 4 (Table 4.3)

\section{CALIFORNIA BEARING RATIO (CBR) TEST}

The Californian Bearing Ratio (CBR) test is a test used to evaluate the strength of cohesive material used for roads and pavements specified in soil material. The results of these tests are used to design the thickness of pavement and its component layers for the type of mix. This is one of the important tests used to create the design for road pavement.

The California Bearing Ratio (CBR) test is a simple strength test that dominates on the bearing capacity of the base material or unbounded material with required material gradation and MDD.

The CBR test is used in pavement construction for the strength measure, elastic modulus and moisture durability for all layers required by the road works. CBR tests were performed as specified in ASTM D1883 on the six samples compacted at their corresponding OMCs.

The CBR values are tabulated in Figure 5, the specification of CBR for road base and 
subbase is $80 \%$ and $70 \%$ respectively.

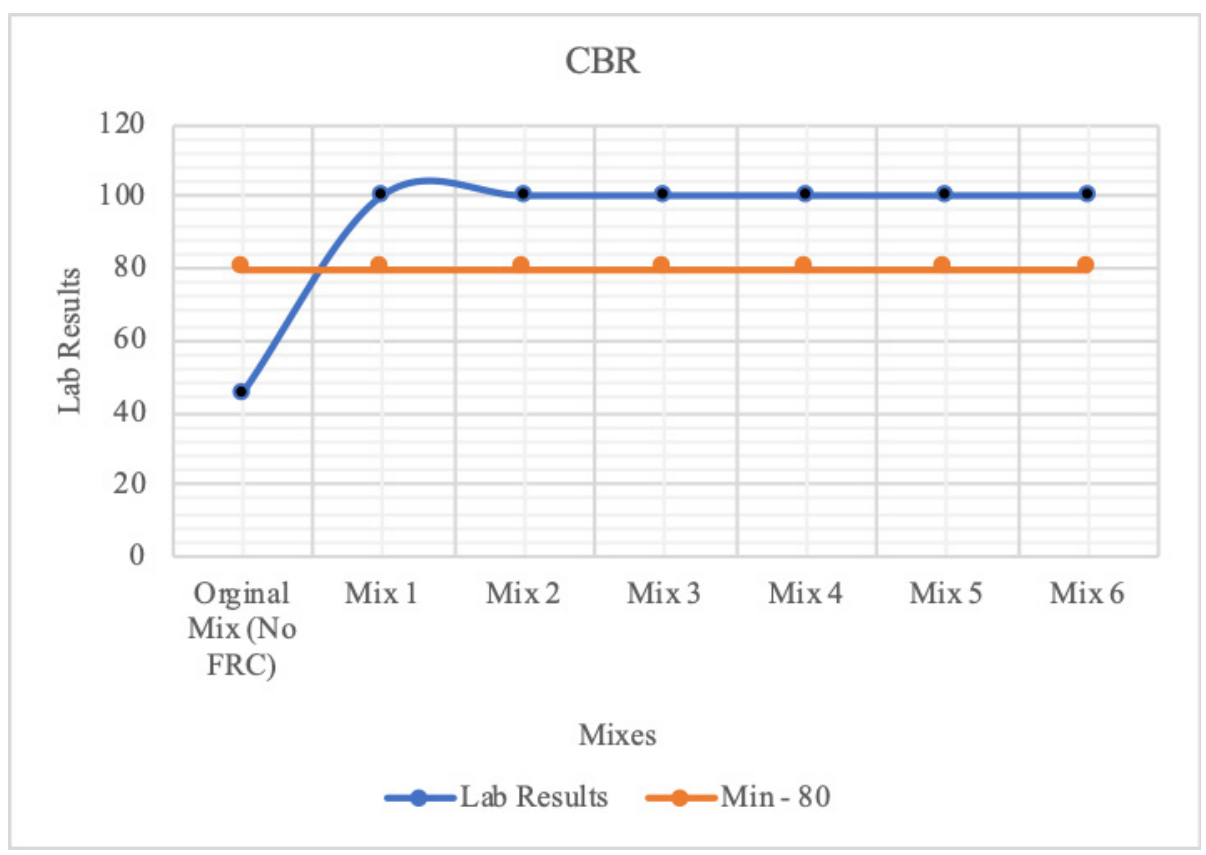

Figure 5: CBR Tests Results

The higher CBR, the higher stability and higher quality however more durability. As presented by the graph that the mix with no FRC material fall beyond the minimum requirement as per (QCS, 2014) section 6 part 4 (table 4.3), while adding FRC material shows that it is the only material that can replace the Gabbro to upgrade and increase the CBR percentage to higher value as per QCS.

\section{SOIL CLASSIFICATION}

AASHTO as per AASHTO SOIL Classification System (from ASHTO M 145 or ASTM D3282) has classification parameters used to identify various soil mixes based on the gradation and the plasticity index quality test. In highway construction these classifications are used and applied to our original and upgraded sample with FRC material to provide the results as tabulated in Table 3 .

Table 3: Classification of the 6 Soil Mixes with *FRC material

\begin{tabular}{|l|c|c|}
\hline \multirow{2}{*}{ AASHTO Classification: } & Table 1 & Table 2 \\
\cline { 2 - 3 } & A-1 & A-1-a \\
\hline \multicolumn{2}{|c|}{ Stone Fragments, Gravel and Sand (Excellent to Good) } \\
\hline
\end{tabular}

*FRC: Fine recycled concrete

While the original material without the fine crushed, concrete had been classified also to verify the classification type as per Table 4 . 
Table 4: Classification of The Original Material without *FRC material

AASHTO Classification:

\begin{tabular}{|l|l|}
\hline Table 1 & Table 2 \\
\hline A-2 & A-2-7 \\
\hline
\end{tabular}

\section{Silty or clayed gravel and sand (Excellent to Good)}

*FRC: Fine recycled concrete

Adding the FRC material not only upgrade the material quality from the failed zone as per (QCS, 2014), also it upgrades the material classification from Silty or clayed gravel and sand to a Stone Fragment gravel and sand.

\section{CONCLUSION}

As per the material size distribution, Atterberg limits, sand equivalent, maximum dry density and California bearing ratio tests which shows that adding a $20 \%$ fine crushed concrete material is a versatile material and it will delineate the capability to increase the quality for the susceptible material as the gradation is in the required minimum and maximum percentage, Atterberg limits upgraded from a high plasticity index to a non-plastic material as the fine crushed concrete material is a non-plastic material, sand equivalent increased from very low percentage to a higher percentage as the sand equivalent for the fine crushed concrete is high as well as the acceptable results for maximum dry density and the CBR which specify the requirements mentioned in (QCS, 2014) section 6 part 4.

It is evident that the various samples with FRC supersede the typical mix (with no FRC) on every level. The comparison was conducted for the results of various testing methods stipulated by the (QCS, 2014) for mix designs. This paper shows in detail that the results for every test conducted prove the mix designs containing FRC to better the typical sample. That is on a technical level, although the benefits stretch to provide environmental, economic, and theoretical Value. With consideration of the growing demand for recycling, waste management and cost control management approaches such as project management, six sigma, and lean construction management. Recycling concrete waste by crushing and utilizing the material not only proves as a solution to reducing pollution and saving resources while also serves as a solution for bettering the quality of mix designs in road construction to improve specifications and meeting regulations. All these benefits come with reduced costs for both the Qatari government and the contractors in Qatar. In laymen terms, we call this a win-win situation and other advantages the crushed concrete can be used as a replacement for washed and dune sand within different mixes for different road construction practices.

\section{REFERENCES}

Dickenson, S. E. (1996). Soils in construction. Fourth Edition, Chapter 4, page 255, R. R. Donnelley \& sons company, New Jersey.

Deal, T. A. (1997). What it costs to recycle concrete: C\&D Debris Recycling, V. 4, no. 6.

FOHS, D. G. (1990). Use of waste and by products in highway construction. Transportation research record, 1288. 
Goonan, T. G. (1998). Aggregates from natural and recycled sources-Economic assessments for construction applications, (U.S. Geological Survey), Circular 1176.

Kelly, T. (1996), Crushed Cement Concrete Substitution for Construction Aggregates-A Materials Flow Analysis, (U.S. Geological Survey), Circular 1177.

Snyder, M. B. (1995). Use of crushed concrete products in Minnesota pavement foundations, Technical report documentation, (MN/RC-96/12). 